\title{
Liver Function and Structure in Rats Treated Simultaneously with Cadmium and Mercury
}

\author{
Samir Haouem ${ }^{1 *}$, Issam Chargui ${ }^{2}$, Mohamed Fadhel Najjar ${ }^{3}$, Badreddine Sriha ${ }^{4}$, Abdelhamid El Hani ${ }^{1}$ \\ ${ }^{1}$ Department of Physiology, Faculty of Medicine of Monastir, Monastir, Tunisia; ${ }^{2}$ Laboratory of Histology Cytology and Genetics, \\ Faculty of Medicine of Monastir, Monastir, Tunisia; ${ }^{3}$ Laboratory of Biochemistry, University Hospital of Monastir, Monastir, Tuni- \\ sia; ${ }^{4}$ Laboratory of Pathology, University Hospital Farhat Hached of Sousse, Sousse, Tunisia. \\ Email: *samirzeineb@yahoo.fr
}

Received August $2^{\text {nd }}, 2012$; revised November $2^{\text {nd }}, 2012$; accepted November $12^{\text {th }}, 2012$

\begin{abstract}
The effect of cadmium chloride (150 mg/l) and mercury (II) chloride $(80 \mathrm{mg} / \mathrm{l})$ either alone or in combination in drinking water for 4 weeks on function and structure of the liver of male rats was studied. Results indicated that the ratio of liver weight to body weight and the activities of serum alanine aminotransferase, aspartate aminotransferase and alkaline phosphatase noted in rats co-exposed to cadmium and mercury were intermediate between those noted in the individually metal treated rats. The histopathological study showed that the individual metal and the combined metal treatments caused severe liver damage. The degree of these changes noted in rats co-exposed to cadmium and mercury was not higher than those signalized in individual treatment. The biochemical and the histological changes observed in rats co-exposed to cadmium and mercury show that there is not an additive effect between these two metals.
\end{abstract}

Keywords: Cadmium; Mercury; Liver Toxicity; Rat

\section{Introduction}

Cadmium and mercury are considered among the most important toxic metals. Cadmium is present in the environment as a result of industrial and agricultural practices [1]. Cadmium is listed among the hazardous chemicals because it can enter the food chain [2] and it has a long biological half-life (about 30 years) in humans $[3,4]$. The "Itai-Itai" disease was caused by cadmium intoxification in Japan and is a notorious syndrome including severe bone deformities and chronic renal disease [5]. Mercury is derived from natural sources such as volcanic eruption, dissolution and volatilization from rocks, soils and sediment, and from human activities such as combustion of fossil fuels, incineration of waste, mining and industrial discharge [6]. The most famous case of contamination with organic mercury is the Minamata case in the 1950/60s in Japan. People who consumed food mainly fish, contaminated with methylmercury presented several health problems, especially children exposed to the metal in utero [7]. Liver is a target organ for the accumulation of cadmium and mercury [8]. Several previous studies show that these two metals cause hepatotoxicity [5,9]. The cytotoxicity of these two metals was manifested by the disturbance in the activity of some plasmatic enzymes such as aspartate aminotransferase,

${ }^{*}$ Corresponding author. alanine aminotransferase, alkaline phosphatase and lactate dehydrogenase. Several morphological changes in hepatic tissue were noted also after intoxication with cadmium [10] and mercury [11].

In real life, the human population is exposed to complex mixtures of contaminants. So, the experimental work with combination of contaminants is more relevant on the human exposure than the work with a single substance. However, for cadmium and mercury there is, to our knowledge, no information regarding the effect of simultaneous intoxication with these two metals on liver function and structure. Therefore, the purpose of this experiment is the study of the combined effect of cadmium and mercury on liver function and structure in the rat.

\section{Materials and Methods}

\subsection{Animals and Treatment}

Male Wistar rats, weighing $132 \pm 11$ g ( 6 - 8 weeks old), purchased from Siphat (Ben Arous, Tunisia), were used in this study. Animals were housed individually and feed and water were provided ad libitum. After a period of at later 1 week acclimatizing, animals were divided into four groups (4 animals each):

1) Control group: animals consumed distilled water as 
drinking water.

2) Cadmium group: animals consumed a solution of cadmium chloride $\left(\mathrm{CdCl}_{2}\right)(150 \mathrm{mg} / \mathrm{l})$ as drinking water.

3) Mercury group: animals consumed a solution of mercury (II) chloride $\left(\mathrm{HgCl}_{2}\right)(80 \mathrm{mg} / \mathrm{l})$ as drinking water.

4) Cadmium-mercury group: animals consumed a solution of $\mathrm{CdCl}_{2}(150 \mathrm{mg} / \mathrm{l})$ and $\mathrm{HgCl}_{2}(80 \mathrm{mg} / \mathrm{l})$ as drinking water.

Metal solutions were prepared in distilled water.

After 4 weeks of treatment, rats were weighed and then euthanized with exsanguinations by severing the brachial artery after anaesthetizing with ether. Blood was collected and centrifuged, and the serum was conserved at $-80^{\circ} \mathrm{C}$. The liver was removed quickly from animals, washed in ice-cold physiological saline, weighed and treated for histopathological study. Animals were maintained during the experimental period in accordance with guidelines for animals care of the "Faculte de Medecine de Monastir", Tunisia (rats were housed in spacious cages in spaced and ventilated room with controlled temperature: $22^{\circ} \mathrm{C} \pm 2{ }^{\circ} \mathrm{C}$ and photoperiod: 12-h light/ dark cycle, and have free access to water and food).

\subsection{Determination of Serum Liver Function Markers}

The liver function was assessed by the determination of the activities of alanine aminotransfrase (ALT), aspartate aminotransferase (AST) and alkaline phosphatase (ALP) in the serum by automat (Synchron CX9 PRO Beckman coulter).

\subsection{Histological Study}

Small liver specimens were placed in Bouin's fixative solution and processed routinely by embedding in paraffin. Tissue sections $(4-5 \mathrm{~mm})$ were stained with periodic acid/Schiff (PAS) and examined under light microscope.

\subsection{Statistics}

Data are expressed as means \pm SE. Statistical analysis was performed to compare treated groups with control group and the combined metal treatment group with the individually metal treatment groups using a one-way analysis of variance (ANOVA). Differences at $p \leq 0.05$ were considered statistically significant.

\section{Results}

The ratio of liver weight to body weight was decreased significantly in the cadmium $(\mathrm{p} \leq 0.01)$ and the combined metal ( $\mathrm{p} \leq 0.05$ ) exposed groups, whereas no change was observed in mercury group compared to control group (Table 1). In combined group, the ratio of liver weight to body weight was intermediate and comparable to those in the individual metal treated groups.

Liver function was evaluated by measuring serum ALT, AST and ALP activities. The serum ALT activity was increased significantly in all the treated rats compared to control group (Table 1). The changes in serum ALT activity observed in the combined metal-exposed group were significantly lower than those induced by cadmium and significantly higher than those induced by mercury.

As shown in Table 1, the serum AST activity was increased significantly in the $\mathrm{CdCl}_{2}(\mathrm{p} \leq 0.001)$ and the combined metal $(\mathrm{p} \leq 0.05)$ exposed groups, whereas no change was observed in $\mathrm{HgCl}_{2}$ exposed group compared to control group. The serum AST activity noted in rats treated simultaneously with $\mathrm{CdCl}_{2}$ and $\mathrm{HgCl}_{2}$ was significantly $(\mathrm{p} \leq 0.01)$ lower than that in $\mathrm{CdCl}_{2}$ treated rats and significantly $(\mathrm{p} \leq 0.05)$ higher than that in $\mathrm{HgCl}_{2}$ exposed rats.

Concerning the serum ALP activity, a decrease in this parameter was noted in all the treated rats compared to control rats (Table 1). The changes in serum ALP activeity observed in the combined metal-exposed group were significantly $(\mathrm{p} \leq 0.05)$ lower than those induced by $\mathrm{CdCl}_{2}$ and significantly $(\mathrm{p} \leq 0.001)$ higher than those induced by $\mathrm{HgCl}_{2}$.

Light microscopic examination indicated a normal structure of the liver in the controls (Figure 1). Treatment with $\mathrm{CdCl}_{2}$ caused severe liver damage including congestion of vessels, vacuolization, polymorphic nuclei

Table 1. Effect of cadmium (150 mg/l) and mercury $(80 \mathrm{mg} / \mathrm{l})$ alone and in combination in drinking water for 4 weeks on ratio of liver weight to body weight and on serum ALT, AST and ALP activities in male rats.

\begin{tabular}{|c|c|c|c|c|}
\hline \multirow{2}{*}{ Groups } & \multicolumn{4}{|c|}{ Parameters } \\
\hline & Ratio of liver weight to body weight (\%) & ALT (U/L) & AST (U/L) & $\operatorname{ALP}(\mathrm{U} / \mathrm{L})$ \\
\hline Control & $4.09 \pm 0.10$ & $49.0 \pm 1.2$ & $101.05 \pm 9.9$ & $307.30 \pm 7.9$ \\
\hline $\mathrm{Cd}$ & $3.37 \pm 0.17^{*}$ & $85.3 \pm 6.3^{* *}$ & $186.3 \pm 5.9^{* * *}$ & $207.5 \pm 12.1^{* * *}$ \\
\hline $\mathrm{Hg}$ & $3.69 \pm 0.15$ & $55.5 \pm 2.0^{*}$ & $109.3 \pm 6.6$ & $284.5 \pm 1.5^{* *}$ \\
\hline $\mathrm{Cd}+\mathrm{Hg}$ & $3.56 \pm 0.18^{*}$ & $72.5 \pm 2.1^{* * * a a b b b}$ & $136.5 \pm 8.9^{* a a b}$ & $251.8 \pm 4.4^{* * * a b b b}$ \\
\hline
\end{tabular}

Data are means $\pm \mathrm{SE} ;{ }^{*} \mathrm{p} \leq 0.05$ in comparison to control group; ${ }^{* *} \mathrm{p} \leq 0.01$ in comparison to control group; ${ }^{* * *} \mathrm{p} \leq 0.001$ in comparison to control group; ${ }^{\text {a }} \mathrm{p} \leq$ 0.05 in comparison to cadmium group; ${ }^{\text {aa }} \mathrm{p} \leq 0.01$ in comparison to cadmium group; ${ }^{\mathrm{b}} \mathrm{p} \leq 0.05$ in comparison to mercury group; ${ }^{\text {bb }} \mathrm{p} \leq 0.001$ in comparison to mercury group; number of rats $=4$ in each group. 
and degenerative hepatocytes (Figure 2). The liver sections of animals treated with $\mathrm{HgCl}_{2}$ showed also a modification in the structure of this organ characterized by necrosis of hepatocytes, vacuolization of the cytoplasm of the hepatocytes, polymorphism of nuclei and tissue and vessel congestions (Figure 3). In the rat treated simultaneously with these two metals, we noted also damage in the hepatic tissue traduced by vacuolation, hypertrophy of hepatocytes, vessel congestions, necrosis and dilated sinusoidal spaces (Figure 4). But the degree of these changes was not higher than those signalized in individual treatment.

\section{Discussion}

To our knowledge, this is the first report showing the effects of simultaneous co-exposure to cadmium and inorganic mercury on the function and structure of the liver of male rats.

In the present study we have observed a significant decrease in the ratio of liver weight to body weight in rats treated with $\mathrm{CdCl}_{2}$ alone. This is in agreement with previous works [5] showing that cadmium causes an atrophy of liver. On the other hand we did not observe any
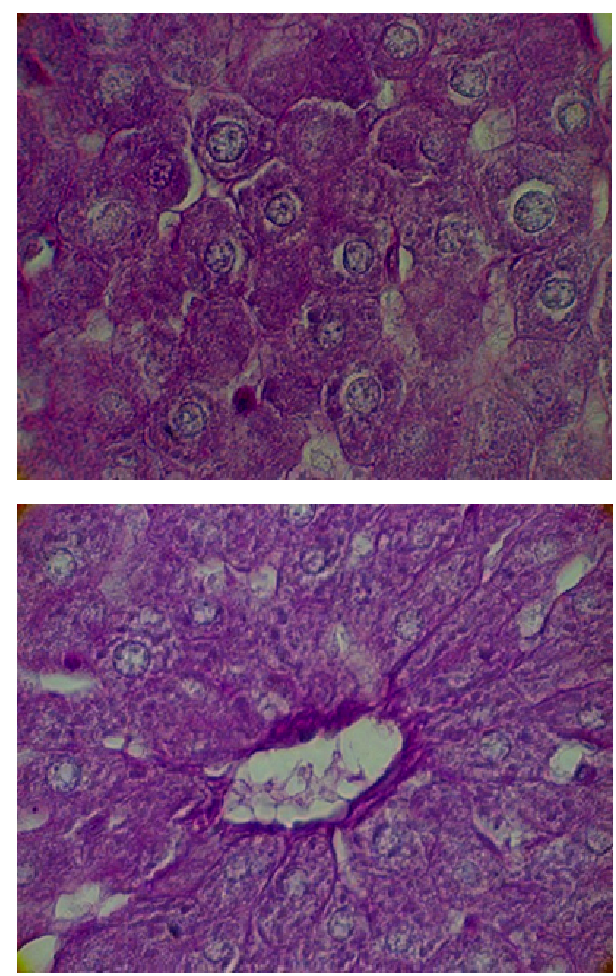

Figure 1. Microscopic structure of liver of a control rat: the organ is organized into lobules with portal triads at the vertices and a central vein in the middle. Within each lobule, hepatocytes are normal with well developed nuclei and arranged into hepatic cords running radiantly from the central vein and are separated by adjacent sinusoids (PAS $\times$ 1000).
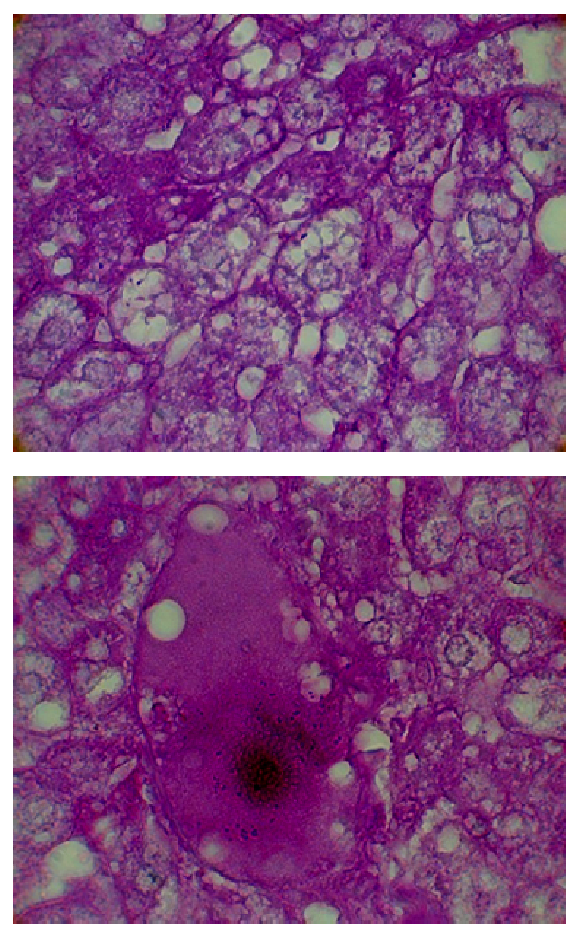

Figure 2. Microscopic structure of liver of rats consumed solution of $\mathrm{CdCl}_{2}(150 \mathrm{mg} / \mathrm{l})$ as drinking water for 4 weeks: the liver sections show vessel congestions, vacuolization, polymorphic nuclei and degenerative hepatocytes (PAS $\times$ 1000).
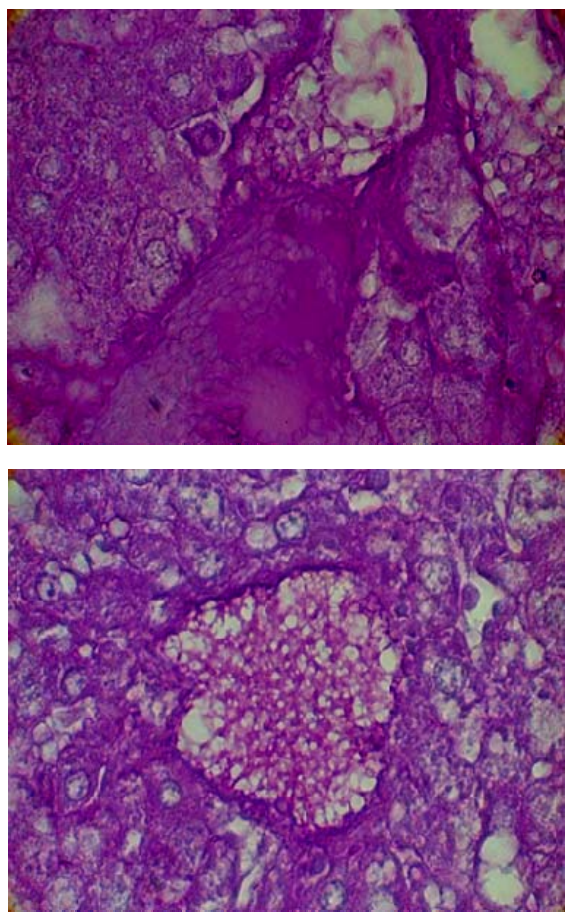

Figure 3. Microscopic structure of liver of rats consumed solution of $\mathrm{HgCl}_{2}(80 \mathrm{mg} / \mathrm{l})$ as drinking water for 4 weeks: the liver sections show necrosis of hepatocytes, vacuolization of the cytoplasm of the hepatocytes, polymorphism of nuclei and tissue and vessel congestions (PAS $\times 1000)$. 

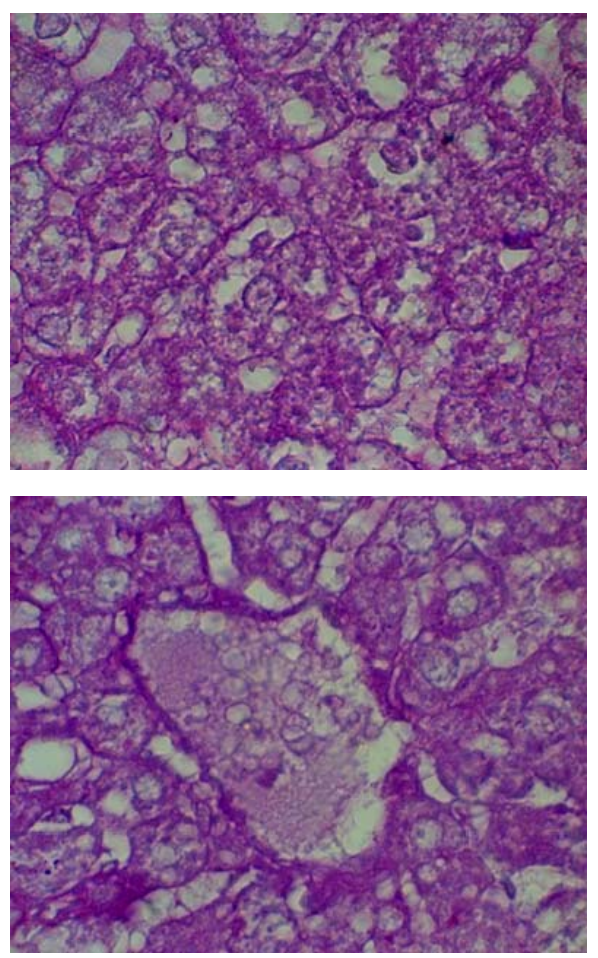

Figure 4. Microscopic structure of liver of rats consumed a solution of $\mathrm{CdCl}_{2}(150 \mathrm{mg} / \mathrm{l})$ and $\mathrm{HgCl}_{2}(80 \mathrm{mg} / \mathrm{l})$ as drinking water for 4 weeks: the liver sections show vacuolation, vessel congestions, necrosis and dilated sinusoidal spaces (PAS $\times$ 1000).

change in the ratio of liver weight to body weight in rats treated with $\mathrm{HgCl}_{2}$ alone. This result may be related to the dose and the duration of the experiment used since the same result was obtained previously with dose of mercury of $50 \mathrm{ppm}$ and for a period up to 10 weeks [12]. The combined treatment group shows an intermediate ratio of liver weight to body weight when compared to the individual metal treated groups, suggesting antagonism effect between cadmium and mercury.

The activities of ALT, AST and ALP in the serum of rats are tested as indicator for hepatic function [13,14]. In our study, the activities of ALT and AST in the serum of cadmium exposed rats were significantly elevated, and the activity of ALP was significantly decreased indicating Cd-related injury to the liver. This result is also reported by other papers $[15,16]$. Previous studies have showed that mercury causes a disturbance in liver function manifested by an increase in serum ALT activiyty [14], and a decrease in ALP activity [17]. In agreement with these findings our result show an increase in serum ALT activity and a decrease in serum ALP activity which reflect that the treatment with $\mathrm{HgCl}_{2}$ caused perturbations in liver function.

In several organs, cell damage is followed by release of a number of cytoplasmic enzymes to the blood, a phenomena that provides the basis for clinical diagnosis
[18]. Therefore, the increase in ALT and AST activities noted in this study may be explained by the leakage of these enzymes from the liver cytosol into the blood stream. On the other hand, the decrease in ALP activity may be due to disturbances in the balance between synthesis and degradation of the enzyme.

The enzymatic disturbances produced by the combined treatment are lower than those produced by $\mathrm{CdCl}_{2}$ alone and higher than those induced by $\mathrm{HgCl}_{2}$. This might be attributed to a competition between these two metals.

In the present work, the structure of liver was evaluated on the basis of histopathological findings. Our results show that $\mathrm{Cd}$ treatment resulted in severe structural changes to the liver. Other investigators [12,19] have noted similar or more pronounced changes in the hepatic tissue under $\mathrm{Cd}$ effect. In rats treated with mercury alone, we noted, also, a modification in the structure of this organ. This is in agreement with the finding of Agrawal et al. [11] who found changes in liver morphology following mercuric chloride administration. In the rat treated simultaneously with these two metals, we noted also morphological changes in hepatic tissue but the degree of these changes was lower than those signalized in individual treatment. This result may be attributed to an antagonistic effect between these two metals.

It is to be noted that combined exposure of $\mathrm{CdCl}_{2}$ and $\mathrm{HgCl}_{2}$ revealed intermediate results in the almost parameters studied. This might due to the competition between the two metals for a single binding site. In fact previous studies [20,21] have showed that both metals inhibit hepatic $\delta$-Aminolevulinate dehydratase $(\delta$-ALAD): a sulfhydryl-containing enzyme that catalyzes the asymmetric condensation of two $\delta$-aminolevulinic acids ( $\delta$-ALA) molecules yielding porphobilinogen,a heme precursor [22]. Consequently, $\delta$-ALA-D inhibition may perturb heme-dependent metabolic pathway [23] and can result in the accumulation of 5-aminolevulinic acid, which has some pro-oxidant activity [24-26]. Nogueira et al. [27] show also that the prevailing mechanism for $\delta$ ALA-D inhibition by cadmium and for mercury is likely related to the formation of stable mercaptides with dALA-D sulfhydryl groups. This means that there is probably a common point between the mechanisms of actions of these two metals.

In summary, this study provides added information on the consequences of simultaneous exposure to cadmium and inorganic mercury on the liver function and structure. From the above results it is clear that there is not an additive effect between these two metals.

\section{Acknowledgements}

We thank Mme TEKAYA Imène for her assistance in enzymes analysis. This work was supported by the unit of Research No. 04/UR/09-03 of the general direction of scientific and technological research of Tunisia. 


\section{REFERENCES}

[1] S. Satarug, J. R. Baker, S. Urbenjapol, M. R. HaswellElkins, P. E. B. Reilly and D. J. Williams, "A Global Perspective on Cadmium Pollution and Toxicity in NonOccupationally Exposed Population," Toxicology Letters, Vol. 137, No. 1-2, 2003, pp. 65-83. doi:10.1016/S0378-4274(02)00381-8

[2] H. W. Schenkel, "Nutritive Beeinflssung des Stoffwechsel-Verhalten von Cadmium bei Rind und Schwein," Habilitationsschrift Hohencheim, 1988.

[3] G. C. Cotzias, D. C. Borg and B. Selleck, "Virtual Absence of Turnover in Cadmium Metabolism: Cd109 Studies in the Mouse," American Journal of Physiology, Vol. 201, No. 5, 1961, pp. 927-930.

[4] G. F. Nordberg and T. Kjellstrom, "Metabolic Model for Cadmium in Man," Environmental Health Perspectives, Vol. 28, 1979, pp. 211-217. doi:10.1289/ehp.7928211

[5] D. F. Hwang and L. C. Wang, "Effect of Taurine on Toxicity of Cadmium in Rats," Toxicology, Vol. 167, No. 3, 2001, pp. 173-180. doi:10.1016/S0300-483X(01)00472-3

[6] P. L. Goering, D. L. Morgan and S. F. Ali, "Effect of Mercury Vapour Inhalation on Reactive Oxygen Species and Antioxidant Enzymes in Rat Brain and Kidney Are Minimal," Journal of Applied Toxicology, Vol. 22, No. 3, 2002, pp.167-172. doi:10.1002/jat.844

[7] S. Ekino, M. Susa, T. Ninomiya, K. Imamura and T. Kitamura, "Minamata Disease Revisited: An Update on the Acute and Chronic Manifestations of Methyl Mercury Poisining," Journal of the Neurological Sciences, Vol. 262, No. 1-2, 2007, pp. 131-144. doi:10.1016/i.jns.2007.06.036

[8] S. Yannai and K. M. Sachs, "Absorption and Accumulation of Cadmium, Lead and Mercury from Foods by Rats," Food and Chemical Toxicology, Vol. 31, No. 5, 1993, pp. 351-355. doi:10.1016/0278-6915(93)90190-A

[9] I. Bando, M. I. Reus, D. Andrés and M. Cascales, "Endogenous Antioxidant Defense System in Rat Liver Following Mercury Chloride Oral Intoxication," Journal of Biochemical and Molecular Toxicology, Vol. 19, No. 3, 2005, pp. 154-161. doi:10.1002/jbt.20067

[10] A. Koyu, A. Gokcimen, F. Ozguner, D. S. Bayram and A. Kocak, "Evaluation of the Effects of Cadmium on Rat Liver," Molecular and Cellular Biochemistry, Vol. 284, No. 1-2, 2006, pp. 81-85. doi:10.1007/s11010-005-9017-2

[11] R. Agarwal, S. K. Goel, R. Chandra and J. R. Behari, "Role of Vitamin E in Preventing Acute Mercury Toxicity in Rat," Environmental and Toxicology and Pharmacology, Vol. 29, No. 1, 2010, pp. 70-78. doi:10.1016/j.etap.2009.10.003

[12] L. D. Koller, B. V. Stang and M. V. De L. R. Mendez, "Pathology of Toxic Oils and Selected Metals in the MRL/lpr Mousse," Toxicology Letters, Vol. 29, No. 6, 2001, pp. 630-638.

[13] S. A. El-Maraghy, M. Z. Gad, A. T. Fahim and M. A. Hamdy, "Effect of Cadmium and Aluminum Intakeon the Antioxidant Status and Lipid Peroxidation in Rat Tissues," Journal of Biochemical and Molecular Toxicology,
Vol. 15, No. 4, 2001, pp. 207-214. doi:10.1002/jbt.18

[14] M. Kumar, M. K. Sharma and A. Kumar, "A Food Supplement against Mercury Induced Hepatic Toxicity," Journal of Health Science, Vol. 51, No. 4, 2005, pp. 424-430. doi:10.1248/jhs.51.424

[15] M. M. Brzoska, J. Moniuszko-Jakoniuk, B. Pilat-Marcinkiewicz and B. Sawickl, "Liver and Kidney Function and Histology in Rats Exposed to Cadmium and Ethanol," Alcohol and Alcoholism, Vol. 38, No. 1, 2003, pp. 2-10. doi:10.1093/alcalc/agg006

[16] L. Pari and P. Murugavel, "Role of Diallyl Tetrasulfide in Ameliorating the Cadmium Induced Biochemical Changes in Rats," Environmental and Toxicology and Pharmacology, Vol. 20, No. 3, 2005, pp. 493-500. doi:10.1016/j.etap.2005.05.009

[17] M. K. Sharma, R. Patni, M. Kumar and A. Kumar, "Modification of Mercury-Induced Biochemical Alterations in Blood of Swiss Albino Mice by Spirulina fusiformis," Environmental and Toxicology and Pharmacology, Vol. 20, No. 2, 2005, pp. 289-296. doi:10.1016/i.etap.2005.02.006

[18] A. Sundberg, E. L. Appelkwist, G. Dallner and R. Nilsson, "Glutathione Transferase in the Urine: Sensitive Methods for Detection of Kidney Damage Induced by Nephrotoxic Agents in Humans," Environmental Health Perspectives, Vol. 102, Suppl. 3, 1994, pp. 293-296.

doi:10.1289/ehp.94102s3293 doi:10.2307/3431805

[19] E. H. Jihen, M. Imed, H. Fatima and K. Abdelhamid, "Protective Effects of Selenium (Se) and Zinc (Zn) on Cadmium (Cd) Toxicity in the Liver and Kidney of the Rat: Histology and Cd Accumulation," Food and Chemical Toxicology, Vol. 46, No. 11, 2008, pp. 3522-3527. doi:10.1016/j.fct.2008.08.037

[20] J. B. T. Rocha, M. E. Pereira, T. Emanuelli, R. S. Christofari and D. O. Souza, "Effect of Treatment with Mercuric Chloride and Lead Acetate during the Second Stage of Rapid Post-Natal Brain Growth on ALA-D Activity in Brain, Liver and Blood of Suckling Rats," Toxicology, Vol. 100, No. 1-3, 1995, pp. 27-37. doi:10.1016/0300-483X(95)03054-J

[21] M. Farina, R. Brandão, F. S. Lara, F. A. A. Soares, D. O. Souza and J. B. T. Rocha, "Mechanisms of the Inhibitory Effects of Selenium and Mercury on the Activity of d-Aminolevulinate Dehydratase from Mouse Liver, Kidney and Brain," Toxicology Letters, Vol. 139, No. 1, 2003, pp. 55-66. doi:10.1016/S0378-4274(02)00454-X

[22] E. K. Jaffe, "Porphobilinogen Synthase, the First Source of Heme's Asymmetry," Journal of Bioenergetics and Biomembranes, Vol. 27, No. 2, 1995, pp. 169-179. doi:10.1007/BF02110032

[23] E. N. Maciel, R. C. Bolzan, A. L. Braga and J. B. T. Rocha, "Diphenyl Diselenide and Diphenyl Ditelluride Differentially Affect Delta-Aminolevulinate Dehydratase from Liver, Kidney, and Brain of Mice," Journal of Biochemical and Molecular Toxicology, Vol. 14, No. 6, 2000, pp. 310-319.

doi:10.1002/1099-0461(2000)14:6<310::AID-JBT3>3.3. $\mathrm{CO} ; 2-4$ 
[24] R. Neal, P. Yang, J. Fiechtl, D. Yildiz, H. Gurer and N. Ercal, "Pro-Oxidant Effects of Delta-Aminolevulinic Acid (Delta-ALA) on Chinese Hamster Ovary (CHO) Cells," Toxicology Letters, Vol. 91, No. 3, 1997, pp. 169-178. doi:10.1016/S0378-4274(97)03887-3

[25] F. G. Princ, A. A. Juknat, A. A. Amitrano and A. Batlle, "Effect of Reactive Oxygen Species Promoted by Deltaaminolevulinic Acid on Porphyrin Biosynthesis and Glucose Uptake in Rat Cerebellum," General Pharmacology, Vol. 31, No. 1, 1998, pp. 143-148. doi:10.1016/S0306-3623(97)00388-1
[26] M. Yusof, D. Yildiz and N. Ercal, "N-Acetyl-L-Cysteine Protects against Delta-Aminolevulinic Acid-Induced 8Hydroxydeoxyguanosine Formation," Toxicology Letters, Vol. 106, No. 1, 1999, pp. 41-47. doi:10.1016/S0378-4274(99)00014-4

[27] C. W. Nogueira, F. A. Soares, P. C. Nascimento, D. Muller and J. B. T. Rocha, "2,3-Dimercaptopropane-1-Sulfonic Acid and Meso-2,3-Dimercaptosuccinic Acid Increase Mercury- and Cadmium Induced Inhibition of d-Aminolevulinate Dehydratase," Toxicology, Vol. 184, No. 2-3, 2003, pp. 85-95. doi:10.1016/S0300-483X(02)00575-9 